\title{
The anticipated work-family conflict of future business managers: Does gender and maternal employment matter?
}

\author{
J.J. Bagraim* and E. Harrison \\ School of Management Studies, University of Cape Town \\ Private Bag, Rondebosch 7701, Republic of South Africa \\ Jeffrey.Bagraim@uct.ac.za
}

\begin{abstract}
This study investigated the nature and predictors of anticipated work-family conflict (AWFC) amongst business students in South Africa ( $\mathrm{N}=645)$ who intended to both work and start a family. Anticipated work-family conflict is the belief that future demands from work and family will be incompatible. The results indicate moderate levels of anticipated workfamily conflict with differences across gender but no differences across race, socio-economic status, parental employment or parental education level. Further analysis showed an interaction effect between gender and maternal employment in explaining AWFC amongst female students. As expected, the personal factorsof positive affectivity and specific selfefficacy beliefs helped predict significant variance in AWFC. Social context factors did not help explain the variance in AWFC above that explained by demographic and personal variables.
\end{abstract}

*To whom all correspondence should be addressed.

\section{Introduction}

Anticipated work-family conflict (AWFC) is the anticipated inter-role conflict between future work and family roles, predicated on the assumed incompatibility of these roles (Weer, Greenhaus, Colakoglu, \& Foley, 2006). While there is a plethora of literature on work-family conflict, little attention has been paid to anticipated work-family conflict amongst those contemplating life choices (e.g., marriage, children, and career changes) or life transitions (e.g., those preparing to enter the workforce for the first time after completing their studies).

The nascence of the literature on anticipated work-family conflict means that the construct is still theoretically underdeveloped and few empirical studies have been conducted. This is not to imply that no valuable work has been conducted or that no debates have emerged. For example, there is some debate regarding the directionality of AWFC with Cinamon (2006) adopting the bi-directionality found in the work-family conflict literature (from family to work and work to family) and Weer et al. (2006) arguing for the acceptance of a unidimensional construct because young adults with no direct experience of work-family conflict will be unlikely to be able to distinguish different directions of the anticipated conflict between work and family.

Regarding the predictors of work-family conflict, there is no generally accepted overall theory regarding the predictors of work-family conflict from which to extrapolate predictors of AWFC. Personal, social and demographic variables have been extensively investigated in the work-family literature (Eby, Casper, Lockwood, Bordeaux, \& Brinley, 2005) and this suggests that these three categories of variable be examined to help propose predictors of AWFC.

Two personal characteristics are posited as predictors of AWFC: self-efficacy to manage future work-family conflict (SE-FWFC) and positive affectivity (PA). Self-efficacy is an individual's belief that their actions will lead to desired effects, even in the face of adversity (Bussey \& Bandura, 1999) and has been found to be negatively related to workfamily conflict (Hennessy \& Lent, 2008). It is reasonable to expect (in the absence of conclusive empirical data) that students with a high level of self-efficacy to manage future work-family conflict will experience less anxiety about future work-family conflict.

Positive affectivity is a personal disposition that refers to individual differences in the experience of positive emotions. Individuals with a high level of positive affectivity tend to be cheerful, engaged in their activities, joyful, enthusiastic, confident, and alert (Cropanzano, James, \& Konovsky, 1993). Individuals with low levels of positive affectivity tend to be less happy, confident or optimistic about the future. Positive affectivity is stable over time and situation. Individuals tend to experience consistent levels of positive affectivity whether at home or at work (Watson, Clark \& Tellegen, 1988). By extension, a student with high positive affectivity will tend to interpret the prospect of balancing future work and family demands as potentially enriching rather than as a potentially problematic stressor. It is therefore proposed that positive affectivity will influence perceptions regarding anticipated conflict between work and family roles in that students with higher positive affectivity will tend to be less fearful, than students with low 
levels of positive affectivity, about any conflict between their future work and family role responsibilities.

Social-cognitive theory provides a useful theoretical lens that may also prove helpful in helping to determine the predictors of anticipated work-family conflict (Bussey \& Bandura, 1999; Ali \& Saunders, 2006). That is, the selfconcepts that form through social experiences provide a strong socialisation effect that influences students' expectations of their future work-family conflicts and their belief that they will be able to manage this conflict in the future. Relevant social context factors for students include the nature of their parents' employment patterns and level of education. Weer et al. (2006) found that male students' AWFC was positively related to maternal employment but that female students' AWFC was not related to maternal employment patterns. Whether the male and female students experienced family life with their employed mother as a positive or negative experience was not measured.

Parental education may affect students' perception of their own future career and how this may impact on their future work and family interaction. O'Shea and Kirrane (2008) found that AWFC of students did not significantly differ in terms of their mothers' educational level, but a significant negative relationship was found between the students' paternal level of education and AWFC. Barnett, Gareis, James and Steele (2003) investigated maternal education level as a predictor of anticipated career-marriage conflict, a similar but more limited construct, and found no significant relationship. Socio-economic status may also help predict AWFC because students from disadvantaged backgrounds are more likely to vicariously experience their parental role models suffering from work-family conflict exacerbated by their lack of resources (e.g., domestic help) available to more resourced families. No previous research has considered the relationship between socio-economic status and AWFC.

The above gives rise to the following propositions that will be investigated in this study:

1. Personal characteristics (i.e., self-efficacy to manage anticipated work-family conflict and general positive affectivity will explain significant variance in anticipated work-family conflict over and above that explained by demographic characteristics (i.e., gender and race).

2. Socialisation characteristics (i.e., maternal and paternal employment, maternal and paternal education, and socio-economic status) will explain significant variance in anticipated work-family conflict amongst students over and above that explained by demographic and personal characteristics.

3. Female students whose mothers were employed fulltime during the student's childhood will experience significantly more anticipated work-family conflict than those whose mothers were not employed fulltime and this relationship will not apply to male students.

\section{Method}

Applying a cross-sectional descriptive research design, a self-report survey was distributed via electronic mail to business students at a leading South African university. Participation was voluntary and the research protocol was approved by the participating university's ethics in research committee.

\section{Participants}

Participants selected for this study consisted of single, childless business students who expressed their intention to get married in the future. Most (over 97\%) intended to have children, the rest intended to get married but not have children. Student ages ranged between 17 years and 27 years $(M=20,5, S D=1,75)$. The demographic composition of the participants was $49 \%$ female and $60 \%$ black (including those self-identifying as Black African, Coloured and Indian). Most students (58\%) indicated that their mothers had a university degree or diploma with a smaller group $(15 \%)$ reporting that their mothers did not complete Grade 12 . Sixty six percent $(66 \%)$ of the participants' fathers had a tertiary qualification. Eleven percent $(11 \%)$ of the participants reported that they had been raised under conditions of significant disadvantage, with the remainder reporting that they had 'enough' $(61,6 \%)$ or 'more than enough' $(27.5 \%)$ during their childhood. More than half the respondents $(55 \%)$ indicated that they were concerned about future conflict between their work and family responsibilities.

\section{Measures}

Anticipated work-family conflict (AWFC). AWFC was measured by adapting Gutek, Searle and Klepa's (1991) eight item measure of work-family conflict to the future tense. A 5-point Likert response scale was used. Students were expected to think about their expectations of future conflicts between work and family demands. An example of an item from the adapted scale is "After work, I will come home too tired to do some of the things I'd like to do".

Self-efficacy for managing future work-family conflict (SE$F W F C$ ). $S E-F W F C$ was measured using six items adapted from Hennessy and Lent (2008). An example of an item is "How confident are you that you could invest in your job even when under heavy pressure due to family responsibilities". Possible responses ranged from $0=$ "Complete lack of confidence" to $9=$ "Totally confident".

Positive affectivity (PA). PA was measured using all 10 positive affect items from the positive and negative affect schedule, known as PANAS (Watson et al., 1988). A time period of 7 days was with responses over a five-point response scale ranging from 'very little' to 'extremely'.

Background variables. Maternal and paternal education levels (on three levels: less than Grade 12; Grade 12; tertiary qualification), maternal and paternal full-time employment during the student's childhood, overall concern for future work-family conflict, intention to have 
children, race, gender and socio-economic status (SES) were all measured with a series of single items.

\section{Results}

Principle axis factor analysis with varimax normalized rotation using Kaiser's criterion (retaining Eigenvalues $>1$ ) was conducted on all multi-item scales. All the items measuring anticipated work-family conflict (AWFC) loaded on a single factor. One item had a low loading and was removed. Items measuring self-efficacy to manage future work-family conflict (SE-FWFC) loaded onto a single factor. The positive affectivity (PA) items also loaded onto a single factor.

Table 1 shows the correlation analysis and reliability analysis for the variables. The Cronbach's coefficient alpha for all the multi-item scales exceeded .7, the widely accepted threshold of acceptability (Tabachnick \& Fidell, 2007). Pearson correlations between the continuous variables were all highly significant but this may be a result of the large sample size.

Hierarchical multiple regression was used to test the two propositions concerning the prediction of AWFC. The demographic variables, race and gender, were entered first. The personal variables were entered second and the social context variables were entered third. The final regression model is shown in Table 2. The regression model after Step 1 , with the inclusion of race and gender, was not significant and neither predictor was significant (though gender is only marginally not significant, the large sample size, which inflates the probability of obtaining a significant result, militates against over-empathising this). After entering the personal variables (SE-FWFC and PA) in Step 2, the model was significant and gender, SE-FWFC and PA were significant predictors of AWFC (race was not significant predictor). The inclusion of the personal variables in Step 2 made a significant difference to the model $\left(\Delta \mathrm{R}^{2}=.09, \mathrm{p}<\right.$
,0001) and the overall model was significant $\left(\mathrm{R}^{2}=, 10, \mathrm{p}<\right.$ ,0001). After entering the social context variables in Step 3, the overall model was significant $\left(\mathrm{R}^{2}=, 15, \mathrm{p}<.0001\right)$ with gender $(\beta=, 01, p=, 01)$, SE-FWFC $(\beta=-, 23, p<, 0001)$ and PA $(\beta=-, 13, p<, 0001)$ as significant predictors. None of the five socialisation variables were significant in the final model and the inclusion of these variables did not add significantly to the model $\left(\Delta \mathrm{R}^{2}=, 10, \mathrm{p}=, 12\right)$. That is, the final model predicted only $11,5 \%$ of the variance in AWFC, with an effect size indicating a small to medium effect $\left(\mathrm{f}^{2}=\right.$ ,13). The final regression model is shown in Table 2.

Tolerance values for each independent variable were examined and there was no indication of multicollinearity. A normal probability plot of residuals was constructed, which did not indicate any violation of assumptions (Tabachnick \& Fidell, 2007).

Factorial ANOVA (a two-way between-groups analysis of variance) was conducted to investigate the proposition concerning the direct and moderating relationship between gender, maternal employment and AWFC (Proposition 3). Table 3 details the results of this analysis. The interaction effect between maternal employment and gender was statistically significant, $\mathrm{F}(1,636)=5,51, \mathrm{p}=, 02$. There was also a statistically significant main effect for maternal employment, $\mathrm{F}(1,636)=4,58, \mathrm{p}=, 03$. However, the effect sizes (partial eta-squared) for both these significant effects were small (Tabachnick \& Fidell, 2007). The main effect for gender did not reach statistical significance, $F(1,636)=$ $2,13, p=16$. Figure 1 shows the direction and influence of gender and maternal employment on AWFC, it clearly illustrates that female students whose mothers worked fulltime experienced significantly less AWFC than female students whose mothers did not work full-time, and that this is not significant for male students.

Table 1: Means, standard deviations, correlation and reliability coefficients

\begin{tabular}{llllll}
\hline Variable & M & SD & $\mathbf{1}$ & $\mathbf{2}$ & \\
\hline$S E-F W F C$ & 6,41 & 1,14 & $(0,85)$ & & \\
$P A$ & 3,39 & 0,90 & $0,30^{*}$ & $(0,88)$ & \\
$A W F C$ & 2,67 & 0,58 & $-0,27^{*}$ & $-0,15^{*}$ & $(0,74)$ \\
\hline
\end{tabular}

Note: $\mathrm{N}=640$ (casewise deletion of missing data); $* \mathrm{p}<, 0001 ; \mathrm{AWFC}=$ Anticipated work-family conflict,

SE-FWFC $=$ Self-efficacy to manage future work-family conflict, PA = Positive affectivity

Table 2: Hierarchical Multiple Regression Analysis: DV = AWFC and proposed predictors

\begin{tabular}{|c|c|c|c|c|}
\hline Variable & beta & SE beta & $t(532)$ & $\mathbf{p}$ \\
\hline \multicolumn{5}{|c|}{ Step 1: Demographic } \\
\hline Gender & 0,10 & 0,04 & 2,4 & 0,01 \\
\hline Race & $-0,05$ & 0,05 & $-1,1$ & 0,28 \\
\hline \multicolumn{5}{|c|}{ Step 2: Personal } \\
\hline$\overline{S E-F W F C}$ & $-0,23$ & 0,04 & $-5,3$ & $<0,001$ \\
\hline$P A$ & $-0,13$ & 0,04 & $-2,9$ & $<0,001$ \\
\hline \multicolumn{5}{|c|}{ Step 3: Social context } \\
\hline MOMWORK & $-0,07$ & 0,04 & $-1,6$ & 0,12 \\
\hline MOMEDUC & 0,03 & 0,05 & 0,7 & 0,51 \\
\hline DADWORK & 0,05 & 0,04 & 1,1 & 0,27 \\
\hline$D A D E D U C$ & $-0,10$ & 0,05 & $-2,0$ & 0,05 \\
\hline SES & 0,05 & 0,05 & 1,1 & 0,27 \\
\hline
\end{tabular}

Note: $\mathrm{N}=542$ (casewise deletion of missing data). AWFC = Anticipated work-family conflict; SE-FWFC = Self-efficacy to manage future workfamily conflict; $\mathrm{PA}=$ positive affectivity, SES = Socio-economic status while growing up; MOMWORK = Maternal employment; MOMEDUC = Maternal level of education; DADWORK $=$ Father's employment; DADEDUC $=$ Father's level of education. beta $=$ the standardised regression coefficients; $\mathrm{SE}$ beta $=$ the standard error of beta. $\mathrm{R}=.338, \mathrm{R}^{2}=.115$, Adjusted $\mathrm{R}^{2}=.100, \mathrm{~F}(9,532)=7.64, \mathrm{p}<.0001, \mathrm{f}^{2}=.13$. 
Table 3: Univariate tests of significance, effect sizes, and powers for AWFC

\begin{tabular}{lllllll}
\hline Variable & SS & df & MS & F & p & Partial eta-squared \\
\hline MOMWORK & 1,496 & 1 & 1,496 & 4,58 & 0,03 & $0,01^{*}$ \\
GENDER & 0,695 & 1 & 0,695 & 2,13 & 0,16 & 0,00 \\
MOMWORK *GENDER & 1,801 & 1 & 1,801 & 5,51 & 0,02 & $0,01^{*}$ \\
Error & 207,824 & 636 & 0,327 & & & \\
\hline
\end{tabular}

Note: MOMWORK = Maternal employment $0=$ mother did not work full-time, $1=$ Mother worked-full time);

Sigma-restricted parameterization, effective hypothesis decomposition; $*=$ small effect size

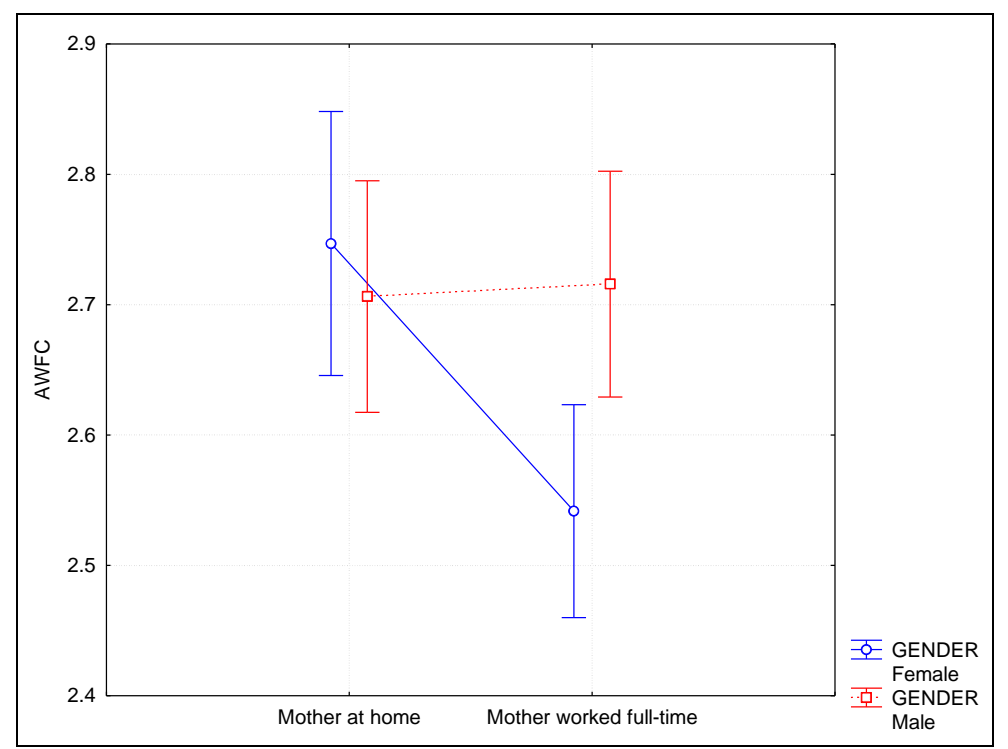

Figure 1: The interaction of gender and maternal employment on AWFC.

\section{Conclusion}

Anticipated work-family conflict was a unidimensional scale indicating that South African students do not distinguish between the family to the work and work to family directionality of AWFC (c.f., Cinamon, 2006; Gutek et al., 1991), which is consistent with many other applications of AWFC (Weer et al., 2006; O'Shea \& Kirrane, 2008; Bu \& McKeen, 2000; Livingston Burley \& Springer., 1996). Similarly, self-efficacy to manage future work-family conflict (SE-FWFC) was a unidimensional scale (Hennessy 7 Lent, 2008). Students have not yet experienced the distinct pressures that participation in work roles and family roles could have on one another and the distinction may therefore not be clear to them (Barnett et al., 2003).

Both race and gender were investigated in this study, with race as a control variable. ANOVA showed no significant main effect for gender, which means that males and female students do not differ in terms of their AWFC; though there is a difference depending on whether the student's mother worked full-time or not. Both Cinamon (2006) and Livingston et al. (1996) found that females had significantly higher levels of AWFC than male students did; they did not consider whether students' mothers had worked full-time during the students' childhood. There was no significant difference between black and white students on AWFC. In South Africa, race may be considered a crude proxy for cultural and socialisation differences not investigated in this study; it was included because cultural differences in experiencing work-family conflict have been found in previous research (Bu \& McKeen, 2000).

The two personal factors investigated in this study emerged as important predictors of AWFC, positive affectivity (PA) and self-efficacy to manage work-family conflict (SEFWFC). As predicted, students with high positive affectivity were less likely to anticipate conflict between future work and family roles. Given the temporal stability of positive affectivity, the results of this study indicate that interventions to reduce anticipated work-family conflict may not be very effective. Nevertheless, this finding emphasises the relevance of examining dispositional affect in future work-family research. Future research should include both positive and negative affectivity as predictors because there is a cogent argument that negative affect, the general tendency to be anxious and fearful, may be an even stronger predictor of AWFC than positive affectivity. Students' belief that they will be able to manage future work-family conflict was a significant predictor of AWFC. This is reassuringly consistent with the known relationship between general self-efficacy and workplace success (Judge $\&$ Bono, 2001). These findings may encourage universities to design programmes that help foster self-efficacy to manage future work-family conflict amongst students. The findings may also help students consider the issue and make choices that sustain their preferences (Byron, 2005).

The social context variables, including maternal full-time employment during childhood, were not significant predictors of the variance in students' level of AWFC over 
and above the demographic and personal variables entered in earlier steps of the regression model. The interaction between gender and maternal employment in the prediction of AWFC is particularly interesting because it suggests that female business students who had working mothers that worked full-time and inevitably needed to balance work and family demands drew a positive lesson from this that may have helped reduce their anticipated conflict between work and family. Further research is needed to investigate how this finding articulates with levels of maternal coping with work-family conflict and the influence of this on students' self-efficacy beliefs. This study confirms previous findings regarding the importance of considering maternal employment patterns during the students' childhood (Barnett et al., 2003; O'Shea \& Kirrane, 2008). Of further interest is the strong suggestion that socialisation into the world of work begins in childhood, through an extensive social learning process, and that the attitudes and values formed during this socialisation process endure into later life.

\section{References}

Ali, S.R. \& Saunders, J.L. 2006. 'College expectations of rural Appalachian youth: An exploration of social cognitive career theory factors', The Career Development Quarterly, 55: $38-51$.

Barnett, R.C., Gareis, K.C., James, J.B. \& Steele, J. 2003. 'Planning ahead: College seniors' concerns about careermarriage conflict', Journal of Vocational Behavior, 62: $305-$ 319.

Barnett, R.C. \& Hyde, J.H. 2001. 'Women, men, work, and family', American Psychologist, 56: 871-796.

Bu, N. \& McKeen, C.A. 2000. 'Work and family expectations of the future managers and professionals of Canada and China', Journal of Managerial Psychology, 15: 771-794.

Bussey, K. \& Bandura, A. 1999. 'Social cognitive theory of gender development and differentiation', Psychological Review, 106: 676-713.

Byron, K. 2005. 'A meta-analytic review of work-family conflict and its antecedents', Journal of Vocational Behavior, 67: 169-198.

Cinamon, R.G. 2006. 'Anticipated work-family conflict: Effects of gender, self-efficacy and family background', The Career Development Quarterly, 54: 202-215.

Cropanzano, R., James, K. \& Konovsky, M.A. 1993. 'Dispositional affectivity as a predictor of work attitudes and job performance', Journal of Organizational Behaviour, 14: 595-606.

Cunningham, M. 2001. 'The influence of parental attitudes and behaviors on children's attitudes toward gender and household labor in early adulthood', Journal of Marriage and Family, 63: 111-122.
Eby, L. T., Casper, W. J., Lockwood, A., Bordeaux, C. \& Brinley, A. (2005). 'Work and family research in IO/OB: Content analysis and review of the literature(1980-2002)', Journal of Vocational Behavior, 66:124-197.

Gutek, B.A., Searle, S. \& Klepa, L. 1991.'Rational versus gender role expectations for work-family conflict', Journal of Applied Psychology, 76: 560-568.

Hennessy, K.D. \& Lent, R.W. 2008. 'Self-efficacy for managing work family conflict: Validating the English language version of a Hebrew scale', Journal of Career Assessment, 16: 370-383.

Judge, T.A. \& Bono, J.E. 2001. 'Relationship of core selfevaluation trains-self-esteem, generalized self-efficacy, locus of control, and emotional stability-with job satisfaction and job performance: A meta-analysis', Journal of Applied Psychology, 80: 80-92.

Larsen, T.P. 2004. 'Work and care strategies of European families: Similarities or national differences?', Social Policy and Administration, 38: 654-677.

Livingston, M.M., Burley, K. \& Springer, T.P. 1996. 'The importance of being feminine: Gender, sex role, occupational and marital role commitment, and their relationship to anticipated work-family conflict', Journal of Social Behavior and Personality, 11:179-192.

O'Shea, D. \& Kirrane, M. 2008. 'The transmission of work-related attitudes: A social learning analysis', Journal of Managerial Psychology, 23: 524-557.

Tabachnick, B. G., \& Fidell, L. S. 2007. Using multivariate statistics $5^{\text {th }}$ Edition. Boston: Pearson Education.

Watson, D., Clark, L.A. \& Tellegen, A. 1988. 'Development and validation of brief measures of positive and negative affect: The PANAS Scales', Journal of Personality and Social Psychology, 54: 1063-1070.

Weer, C.H., Greenhaus, J.H., Colakoglu, S.N. \& Foley, S. 2006. 'The role of maternal employment, role-altering strategies, and gender in college students' expectations of work-family conflict', Sex Roles, 55: 535-544. 
